\title{
PERCEPÇÕES A RESPEITO DO ACOLHIMENTO NA ATENÇÃO PRIMÁRIA NO MUNICÍPIO DO RIO DE JANEIRO
}

\author{
PERCEPTIONS ABOUT USER INTAKE IN PRIMARY CARE IN THE CITY OF RIO DE JANEIRO
}

\author{
Tarciso Feijó da Silva ${ }^{a^{*}}$, Valéria Ferreira Romano ${ }^{b^{* *}}$ \\ atarcisofeijo@yahoo.com.br, ${ }^{b}$ valromano@uol.com.br \\ *Universidade do Estado do Rio de Janeiro - Rio de Janeiro (RJ), Brasil \\ **Universidade Federal do Rio de Janeiro - Rio de Janeiro (RJ), Brasil
}

Data de recebimento do artigo: 07/11/2015

Data de aceite do artigo: 03/03/2016

\section{RESUMO}

Introduçáo: Este artigo abarca questôes que envolvem o acolhimento na atençáo primária no município do Rio de Janeiro. Objetivo: Examinar a prática dos profissionais de duas unidades de atenção primária nesse município e apresentar fragilidades percebidas e referidas por esses profissionais relacionadas com a operacionalizaçáo do acolhimento. Métodos: A pesquisa foi desenvolvida por meio de técnicas de observação sistemática e entrevista semiestruturada e analisada considerando as referências da Análise de Conteúdo apoiadas em Bardin. Resultados: Foram encontrados problemas na construçáo da capacidade resolutiva dos profissionais e dificuldades na integração relacional entre profissionais da Estratégia Saúde da Família e do Núcleo de Apoio à Saúde da Família, refletindo em problemas na condução da coordenação do cuidado. Conclusáo: $\mathrm{O}$ reconhecimento de tais fragilidades, na prospecçáo de impulsionar reflexôes e açôes, dimensiona a expectativa de que a atenção primária no município do Rio de Janeiro possa se constituir na construçáo de parâmetros de enfrentamento sobre seu processo de trabalho, buscando estratégias de apoio institucional, da equipe e dos usuários para a gestáo do acolhimento.

Palavras-chave: Acolhimento; Saúde da Família; atenção primária em saúde.

\section{ABSTRACT}

Introduction: This article covers issues involving user intake in primary care in the city of Rio de Janeiro, Brazil. Objective: To examine the practice of professionals from two primary care units in that city and present weaknesses perceived and referred by these professionals regarding the operationalization of the intake. Methods: The research was developed through systematic observation techniques and semi-structured interviews, and it was analyzed considering the references of Content Analysis supported by Bardin. Results: Problems in the construction of the response capacity of professionals were found, as well as difficulties in the relational integration between professionals of the Family Health Strategy and Family Health Support Center, reflecting in problems in the conduction of the coordination of care. Conclusion: The recognition of those weaknesses, in the prospect of boosting reflections and actions, scale the expectation that primary care in the city of Rio de Janeiro may be constituted in the construction of coping parameters on their work process, seeking strategies of institutional support, of the staff, and of users to manage the intake.

Keywords: User intake; Family Health; primary health care. 


\section{Introdução}

O acolhimento é um conceito potencialmente polissêmico, uma vez que é compreendido de diferentes maneiras por diversos autores, e, apesar de existirem colocaçóes divergentes entre si, em sua maioria elas são complementares. Neste artigo, o acolhimento será visto não apenas como uma abordagem humanizada, respeitosa e comprometida que deve estar presente na relação profissional-usuário, mas também como um recurso para a garantia do acesso aos serviços disponíveis pela atenção primária em saúde (APS), já que por meio das demandas por cuidado é possível planejar açôes e orientar os serviços de saúde.

Assim, o acolhimento alavanca o processo de organização e efetivação da integralidade, sendo um instrumento fundamental para operacionalizar a acessibilidade e o acesso, o que amplia as razóes para que sejam compreendidas as dinâmicas que o envolvem e, consequentemente, a utilização que se faz dele no processo de trabalho na APS ${ }^{1}$.

Para melhor problematizar sobre as implicações do acolhimento e seu potencial para contribuir com o processo de trabalho na APS, é necessário compreender as distintas dimensóes que ele assume nesse ponto de atençáo.

A gestáo da agenda na Estratégia Saúde da Família (ESF) pode ser organizada de diversas maneiras, e embora o acesso avançado pressuponha um mínimo de agendamento prévio, muitas equipes ainda se organizam a partir da demanda programada, quando são previamente agendadas as consultas. Assim, a demanda programada se diferencia da chamada demanda espontânea, principalmente porque esta representa a necessidade autopercebida do usuário para uma resolução imediata de seus problemas, o que nem sempre é possível.

Outra demanda para o preenchimento da agenda tem sido proveniente da busca ativa, que, sendo um movimento dos profissionais em direção ao território, pressupõe um prévio diagnóstico individual (ou coletivo) referente a um problema de saúde que precisa ser abordado.

Podemos inferir, portanto, o quanto é importante que haja uma integração entre as demandas programada e espontânea para que as necessidades de saúde e as açóes de prevenção e promoção possam ser planejadas e realizadas, identificando situaçóes de risco e/ou vulnerabilidade à saúde, justificando o desenvolvimento de atividades coletivas e individuais ou familiares na comunidade ${ }^{2}$.

A existência de uma tensão permanente entre demanda programada e espontânea revela a influência da Vigilância em Saúde no planejamento de ações dentro da lógica da ESF3. Alguns autores defendem, assim, a Vigilância em Saúde como uma "forma de atuação que tem em vista a continuidade, ou seja, o constante monitoramento da saúde-doença dos grupos populacionais", ao contrário de intervençôes pouco efetivas que se orientam em "fatores mais importantes" selecionados pelos profissionais ${ }^{4}$.

Nesse âmbito, o acolhimento é considerado um instrumento que compóe o processo de trabalho em saúde e significa uma forma de exercer a visão da determinação social sobre o processo saúde-doença, ainda que na dimensão individual ${ }^{3}$.

No cotidiano do trabalho na ESF, o acolhimento tem se apresentado como fundamental para a organizaçáo do atendimento à demanda espontânea, principalmente no modelo do acesso avançado, correndo o risco, muitas vezes, de se tornar uma prática centrada na queixa clínica, podendo levar a uma consulta nos modelos tradicionais, ou seja, pouco centrada na pessoa ${ }^{5}$. Por sua vez, reiteramos o acolhimento não só como acesso à demanda espontânea, mas também no sentido de aceitação do usuário como sujeito de direitos e desejos, com o qual se faz necessário estabelecer boa comunicação e relacionamento profissional, a fim de fundar uma relação de compromisso e confiança mútua ${ }^{6}$.

Ainda na compreensão sobre os elementos polissêmicos que compóem o conceito de acolhimento, temos sua interação com a integralidade, que, prevista pelo SUS, desloca o acolhimento para um sentido de "resposta ao sofrimento do paciente que procura o serviço de saúde, e um cuidado para que ela não seja a redução ao aparelho ou sistema biológico deste, pois tal redução cria silenciamentos" 2 . Assim, a integralidade presente no encontro, na conversa e na atitude dos profissionais alavanca o acolhimento para além das demandas explícitas dos usuários.

Dessa maneira, por se tratar de uma ação complexa, o acolhimento exige do profissional certa clareza no estabelecimento de prioridades, pois o que está em questão é atender a todos com equidade, ressaltando, assim, o trabalho em equipe como estratégia de prática desse instrumento.

Segundo Ribeiro et al. ${ }^{7}$, acolher "não significa atender a demanda espontânea em detrimento das açóes para prevenção de agravos e promoção da saúde". Seu objetivo é "orientar o fluxo de demanda, sem risco de descrédito frente à comunidade, devido a atendimentos negligenciados"'. O acolhimento, visto assim, seria capaz de processar atitudes e comportamentos tanto dos usuários como dos membros da equipe, na medida em que possibilita a troca de uma postura de indiferença para uma atitude de solidariedade .

Contudo, ainda que o acolhimento consista em uma tecnologia que possibilite mudar o processo de trabalho em saúde, procurando qualificar a escuta e se comprometer com a resolutividade dos problemas da população, algumas dificuldades na sua operacionalização têm sido apontadas na literatura, tais como: falta de recursos 
humanos para operacionalizá-lo, excesso de demanda, falta de interesse dos profissionais, falta de articulação da equipe, postura não acolhedora, sobrecarga do trabalho do enfermeiro, manutenção do modelo médico-centrado e resolutividade inferior à esperada?

Dentro desse contexto, o objetivo deste artigo é examinar a prática dos profissionais de duas unidades de atenção primária no município do Rio de Janeiro e apresentar fragilidades percebidas e referidas por esses profissionais relacionadas com a operacionalização do acolhimento.

\section{Metodologia}

Apresentamos neste artigo os resultados de uma pesquisa de campo, de base qualitativa, que realizou um estudo descritivo e exploratório em duas Unidades Básicas de Saúde (UBS) no município do Rio de Janeiro, entre os meses de julho de 2012 e agosto de 2013, aprovada pelo Comitê de Ética em Pesquisa da ENSP/FIOCRUZ sob o no 182519 , além de ter recebido anuência institucional da Secretaria Municipal de Saúde do Rio de Janeiro. As duas UBS apresentavam modelo de atenção distinto, determinado pela cobertura total ou parcial da populaçáo pela ESF: a primeira, conhecida por unidade módulo A (clínica da família), possuía todo o território coberto pela ESF; por sua vez, a segunda unidade módulo $B$ (centro municipal de saúde) cobria parcialmente o território da $\mathrm{ESF}^{10}$.

A pesquisa considerou as principais políticas prescritas sobre acolhimento e foi realizada por meio de observação sistemática ${ }^{11}$ e entrevista semiestruturada ${ }^{12}$, envolvendo 22 profissionais de diferentes categorias, sendo 11 profissionais de cada unidade: gerente, profissional do Núcleo de Apoio à Saúde da Família (NASF), médico, enfermeiro, dentista, técnico de enfermagem, técnico de higiene dental, agente comunitário de saúde, agente de endemias, auxiliar de serviços gerais e vigia. Os critérios de escolha para as entrevistas foram a formação e o tempo de atuação nas unidades de saúde.

A observação sistemática foi realizada como apoio às entrevistas e tinha como foco identificar a configuração do acolhimento nas duas unidades pesquisadas, sendo realizados dois turnos de observação sistemática em cada unidade, totalizando 20 horas de observação, considerando um roteiro previamente elaborado para esse fim.

A entrevista, por sua vez, foi efetivada buscando identificar as principais questôes relacionadas com o acolhimento referidas pelos profissionais. Um roteiro conduziu as entrevistas, e uma entrevista piloto foi realizada, o que permitiu avaliar a viabilidade do instrumento utilizado para a pesquisa.

A análise dos resultados foi realizada inicialmente por meio de uma leitura flutuante ${ }^{13}$ de todo o material coletado no campo e nas principais referências. Na leitura flutuante surgiram questóes norteadoras, permitindo identificar nas falas dos profissionais termos relacionados com o objetivo da pesquisa. Esses termos foram agrupados em tabelas, que foram organizadas de acordo com duas categorias analíticas: envolvimento com o acolhimento realizado e dificuldade para realização do acolhimento.

Nessas tabelas, considerando a configuração do acolhimento das unidades e a categoria dos profissionais, procuramos identificar por meio de suas falas o seu envolvimento com o acolhimento e as principais fragilidades encontradas para utilização dessa importante ferramenta.

\section{Resultados}

A maioria dos entrevistados tinha mais de um ano de atuação nas UBS. Somente os gerentes das UBS, um médico, um enfermeiro e uma das nutricionistas do NASF possuíam especialização em Saúde da Família. Todos os profissionais cumpriam carga horária semanal de 40 horas.

$\mathrm{O}$ acolhimento, nas duas unidades de saúde, foi observado como tendo, em alguns momentos, similaridades e, em outros, diversidades, revelando o caráter singular da produção em saúde nas relaçóes estabelecidas entre as unidades estudadas. Essa relação foi observada pelo comportamento dos profissionais e usuários, pela postura adotada de acordo com a demanda de atendimento, pelos fluxos existentes na unidade, bem como pela conformação estrutural das unidades associada ao modelo de atenção adotado.

Os usuários procuravam atendimento nas unidades por conta de uma queixa específica ou estavam agendados previamente. Percebeu-se, no entanto, grande fluxo de pessoas que entravam nas unidades para utilização de outros serviços, tais como curativos e imunização, ou com receitas para transcriçáo de rede privada e encaminhamentos para especialidades de outros pontos da rede para agendamento pelo sistema de regulação de vagas da unidade.

$\mathrm{O}$ acolhimento nas unidades estava organizado para possibilitar a escuta dos motivos que levavam o indivíduo a procurar o serviço de saúde naquele momento e dar uma resposta à sua necessidade. Esse acolhimento era realizado na entrada das unidades, nos corredores e em sala específica onde um profissional enfermeiro avaliava a necessidade imediata de atendimento. Havia escala de revezamento para determinado grupo de profissionais que assumiam a responsabilidade por receber e direcionar os usuários dentro das unidades, sendo possível observar quem trabalhava nas unidades e como trabalhavam os profissionais e que condiçóes de trabalho possuíam. 
Nas duas unidades, os profissionais auxiliares de portaria (vigia) e auxiliares de serviços gerais contribuíram muito com o processo de trabalho direcionando os usuários. Por diversas vezes, os usuários abordavam esses profissionais solicitando alguma informação. $\mathrm{O}$ acesso a esses profissionais era fácil pela sua presença constante na entrada e corredores da unidade, o que evidenciava sua disposição em ajudar, tornando-se por vezes a referência para a "primeira escuta" aos usuários nas unidades. Uma atenção diferenciada foi dada ao profissional agente comunitário de saúde (ACS) que atuava nas unidades, e o que vimos foi: todos os ACS possuíam alguma identificação - ou estavam uniformizados ou com crachá institucional -, assumindo a porta de entrada como facilitadores do acesso (pessoa responsável por organizar a porta de entrada das unidades evitando acúmulo de usuários e fila de espera para atendimento; nas falas dos profissionais, o facilitador do acesso foi identificado como "posso ajudar") e a recepção da unidade, recebendo os usuários de acordo com a equipe de referência. Realizavam a primeira escuta, identificavam a necessidade do usuário, encaminhavam para setor específico visando a realização de algum procedimento ou para sala da unidade reservada para atendimento de um profissional enfermeiro que realizava avaliaçáo de risco e vulnerabilidade quando o usuário entrava na unidade por demanda espontânea.

No entanto, algumas fragilidades foram observadas e referidas pelos profissionais por meio das entrevistas, possibilitando a seguinte sistematização:

1. Pouca capacidade resolutiva dos profissionais que atuam na APS:

$O$ acolhimento aqui da unidade ele tem um certo déficit porque alguns dos ACS eles não tem preparo para estar ali na frente. Então quando algum paciente chega ali na frente às vezes ele não quer nada ele só quer conversar, mas o ACS por ficar nervoso por ter uma fila muito grande ele acaba não prestando muita atenção no que o paciente quer e encaminha ele para outra sala que não tinha nem necessidade dele aparecer (TÉCNICO DE ENFERMAGEM).

Então, está aumentando assim o grau de complexidade de atendimento do paciente em atenção básica e isso está dificultando a gente no trabalho que deveria ser assim de profilaxia. A gente não está conseguindo chegar ao tempo de profilaxia infelizmente por conta dessa diferença (MÉDICO).

2. Dificuldade de se responsabilizar pela demanda buscando responder suas necessidades:

Porque acho assim que o acolhimento conta muito com a colaboração de cada um dos profissionais. Qualquer pessoa que esteja na unidade e que tenha boa vontade, que saiba o que a pessoa precisa, pode ajudar só que eu acho que nem sempre a gente conta com essa boa vontade, ai a pessoa fica andando, procurando respostas que poderia ter encontrado ali mesmo. Às vezes fica esperando sem necessidade, às vezes vai a vários lugares para obter uma informação. Isso satura qualquer pessoa. Infelizmente, eu acho que ainda é um problema muito dificil de ser resolvido por conta disso, que é um fator que precisa da colaboração de cada um de nós. Que a gente tenh a a boa vontade de responder isso e que se a gente não sabe responder que a gente vá buscar resposta com outro profissional. É mais fácil você enquanto profissional falar com outro profissional do que a própria pessoa ficar andando e procurando, então quando você encontra uma pessoa que está com problema que você não sabe resolver, você vai para outro profissional amigo teu, que você saiba que é legal, pra ele ajudar. Eu pelo menos atuo dessa forma. Procuro uma informação para definir o que a pessoa está precisando (TÉCNICO DE ENFERMAGEM).

Vejo muita dificuldade quando falta um profissional da equipe, de quem é que vai acolher. Por mais que a gente tenha tentado criar a equipe irmã, na prática ainda tem muita dificuldade. A gente tem uma demanda espontânea absurda e é uma demanda espontânea de pacientes cadastrados. São aqueles pacientes que culturalmente tem dificuldade de entender o que é a estratégia de saúde da família. São demandas que poderiam aguardar a consulta, mas que preferem chegar e ter aquele imediatismo porque acha que aqui é clinica da família e que ele tem que ser atendido naquele momento e que seu problema é o pior de todos, então eu vejo isso como uma dificuldade. Como acolher e como dar resolutividade a essa demanda espontânea (MÉDICO).

3. Dificuldade para entender o que é projeto terapêutico singular e sua contribuição:

O médico e o enfermeiro têm que estar primeiro à frente desse atendimento inicial. Ele tem que fazer a primeira orientação. Caso eles tenham alguma dificuldade, esse caso vai ser trazido pra uma reunião. Nessa reunião junto com as ACS, junto com o NASF, junto com o médico e o enfermeiro a gente vai discutir, a gente vai traçar um projeto terapêutico. Nesse projeto a gente vai definir se vai ser uma interconsulta, se vai ser uma $V D$ (NUTRICIONISTA - NASF).

4. Dificuldade de acionar mecanismos que possam responder às necessidades dos usuários e atendimento centralizado no profissional médico e enfermeiro:

Ali na frente não é só marcar consulta é você também prestar atenção no que o cadastrado pede. De repente ele náo 
precisa nem de uma consulta. Numa conversa de cinco minutos você consegue resolver o problema dele. Mas as pessoas chegam aqui querendo consulta e às vezes você nem pergunta por que ela quer a consulta. Às vezes não é nada, às vezes você numa conversa consegue resolver e tirar uma dúvida que ele tomaria o tempo do médico de meia hora (TÉCNICO DE ENFERMAGEM).

Vejo isso como uma grande dificuldade. Porque o usuário chega e coloca sua queixa. Ele vai falar da sua maneira, como cidadão, como leigo, ele não tem obrigação de saber se colocar e o ACS se vê limitado frente a essa colocação do usuário e ai ele absorve todo mundo que chega quando muita das vezes não há necessidade de que todos esses que estão chegando ao acolhimento sejam realmente absorvidos para um atendimento (GERENTE).

\section{Pouca integração entre a ESF e o NASF:}

Elas fizeram até uma reunião com a gente no início. Eu vejo eles atendendo, mas não participo assim muito. Eu sei que tem o serviço social, a psicóloga e elas atendem o Bolsa Familia, essas coisas aí. Eu sei que elas fazem esses atendimentos (ENFERMEIRO).

Bom, o NASF é uma proposta maravilhosa, mas ainda não deslanchou porque é muito pouco profissional. Aqui as únicas profissionais do NASF que eu consegui ver atuando bem intensamente, inclusive indo fazer visita domiciliar, foi a psicóloga e a assistente social. Os outros profissionais sinceramente não me pergunte, porque eu não sei se existem aqui (TÉCNICO DE ENFERMAGEM).

6. Fragilidade na coordenação do cuidado relacionada com a dificuldade de encaminhar os usuários para atendimento para outros pontos de atenção.

$O$ acolbimento infelizmente está sendo pra identificar pessoas, pouco para direcionar, porque a gente não tem para onde mandar esta pessoa. Infelizmente, o maior problema hoje do acolhimento é esse, porque acaba a gente atendendo um monte de gente que não deveria ser nosso (MÉDICO).

A sala do Sisreg [Sistema de Regulação] é uma fila o dia inteiro. Aquela burocracia de jogar no sistema para ver o que consegue e o que náo consegue, isso gera uma insatisfação tâo grande. As pessoas ficam ali atrás e eles mostram a revolta deles para qualquer um que passar por ali. Nós somos tachados assim de que não queremos trabalhar. Porque eles acham que cada um que passa ali tem que dar uma solução para eles. E ele está invocado ali naquela sala do Sisreg. Eu vejo as pessoas constantemente reclamando. Poxa, esse exame precisava o mais urgente, porque eu preciso operar e cadê a resolutividade para isso. Então para mim a estratégia ou PS, seja lá o que for, desanda no momento em que você precisa de profissionais especializados e exames mais sofisticados (TÉCNICO DE ENFERMAGEM).

Além das fragilidades apontadas, e considerando as principais diretrizes sobre acolhimento, foi possível observar a importância da humanização como elemento vital para mudança da prática. Escuta qualificada, empatia e conhecimento relacionado com as diferentes linhas de cuidado foram vistos como essenciais para aumento da resolutividade a partir do acolhimento e diminuição das fragilidades encontradas. Por sua vez, a valorização da reunião de equipe e reunióes periódicas com o corpo de profissionais das unidades para discussão sobre o processo de trabalho instalado e a importância do acolhimento para organização deste processo como importantes ferramentas de gestão foram pouco observadas.

\section{Conclusão}

O estudo possibilitou identificar, conforme preconiza a Política Nacional de Humanização, a existência de um acolhimento singular nas UBS pesquisadas. Em cada encontro com o usuário, foi possível perceber um novo modo de produzir saúde que levava em consideração a individualidade dos sujeitos. Isso se deve, em parte, porque cada profissional possuía características próprias e um autogoverno traduzido na produção do cuidado.

No entanto, as fragilidades apontadas revelam que uma etapa de consolidação do fazer saúde ainda precisa ser conquistada, uma vez que o processo de trabalho das unidades e a qualidade dos serviços oferecidos, a exemplo do acolhimento, ainda apresentam rupturas na perspectiva de um olhar para a integralidade do cuidado. Nesse contexto, destacamos a necessidade de maior implicação da gestão nas unidades, solucionando problemas estruturais, além da necessidade de qualificação do apoio institucional na busca de estratégias capazes de contribuir para mudanças a favor da desfragmentação da Rede de Atenção à Saúde.

Ademais, reiteramos a importância do comprometimento, responsabilização e envolvimento de todos profissionais e usuários - diante do acolhimento, que potencialmente inexiste sem a implicação dos sujeitos na produção da saúde.

\section{Referências}

1. Poli P, Norman AH. Acolhimento e (des)medicalização: reflexôes sobre essa prática em um Centro de Saúde. In: Anais do $8^{\circ}$ 
Congresso Brasileiro de Medicina de Família e Comunidade; 15 a 18 de junho de 2006; São Paulo; 2006. 246 p.

2. Gomes MCPA, Pinheiro R. Acolhimento e vínculo: práticas de integralidade na gestão do cuidado em saúde em grandes centros urbanos. Interface Comum Saúde Educ. 2005 Mar-Ago;9(17):287-301.

3. Rivera FJU, Artmann E. Planejamento e gestão em saúde: flexibilidade metodológica e agir comunicativo. Cienc Saúde Colet. 1999;4(2):355-65.

4. Brasil. Programa saúde da família. Brasília: Ministério da Saúde; 2001.

5. Silva RMV, Fracolli LA, Zoboli ELCP. O acolhimento no PSF:da proposta teórica para a operacionalização na prática. Saúde Soc. 2005;14(1):245-6.

6. Campinas LLSL, Almeida MMMB. O acolhimento ao doente com tuberculose: estudo comparativo entre uma unidade de saúde da família e um ambulatório de especialidades médicas [tese]. São Paulo: Universidade de São Paulo; 2003. 222 p.

7. Ribeiro MTAM, Fiuza TM, Lima EBJ. Acolhimento virtual: melhor acessibilidade à Estratégia de Saúde da Família. In:
Anais do $8^{\circ}$ Congresso Brasileiro de Medicina de Família e Comunidade; 15 a 18 de junho de 2006; São Paulo; 2006. $243 \mathrm{p}$.

8. Pinheiro R. As práticas do cotidiano na relação oferta e demanda dos serviços de saúde: um campo de estudo e construção da integralidade. In: Pinheiro R,Mattos RA,organizadores. Os sentidos da integralidade na atenção e no cuidado à saúde. Rio de Janeiro: IMS-UERJ; 2001. p.65-112.

9. Pereira JG, Fracolli LA. Acolhimento e reorganização das práticas em saúde. Saúde Soc. 2005;14(1):23.

10. Rio de Janeiro. Superintendência de Atençẫo Primária. Guia de Referência Rápida. Carteira de serviços: relação de serviços prestados na Atençáo Primária à Saúde/Secretaria Municipal de Saúde e Defesa Civil. Rio de Janeiro: SMSDC; 2011. 128 p.

11. Becker HS. Métodos de pesquisa em ciências sociais. São Paulo: HUCITEC; 1997.

12. Minayo MC. O desafio do conhecimento: pesquisa qualitativa em saúde. 10a ed. São Paulo: HUCITEC; 2007.

13. Bardin L. Análise de Conteúdo. Lisboa: Edições 70; 1977.

\section{Como citar este artigo:}

Silva FT, Romano VF. Percepções a respeito do acolhimento na atenção primária no município do Rio de Janeiro. Rev. Aten. Saúde. 2016;14(49):5-10. 